\section{O Registro Ético no Esporte Socioeducacional: Uma Intervenção Apoiada na Filosofia e Psicologia do Esporte} Ethics in Socioeducational Sports: An Intervention Based on
Philosophy and Sport Psychology

\title{
RESUMO
}

O projeto de extensão "Práticas Esportivas EEFERP: Promovendo valores para crianCristiano Roque ças através do movimento corporal”, foi realizado em uma escola estadual de um bairro periférico de Ribeirão Preto, o Parque Ribeirão Preto, por dois estudantes bolsistas e um supervisor, psicólogo, todos autores deste trabalho. As tarefas corporais e esportivas realizadas visavam diversificar estímulos motores e desafios, solicitar esforços distintos, criar oportunidades e valorizar ocasiões para o exercício da cooperação. A partir deste caso situado de intervenção junto a crianças, buscou-se descrever como a apreensão, elaboração e orientação das experiências esportivas propostas, convergiram ao objetivo de ampliar seus recursos para relacionamentos interpessoais num registro ético. Trata-se de um trabalho descritivo que apresenta situações expressivas da intervenção a partir dos diários de campo dos bolsistas responsáveis pela intervenção ao longo de aproximadamente nove meses.

Palavras-chave: Esporte. Ética. Psicologia.

\footnotetext{
ABSTRACT

The extension project "Práticas Esportivas EEFERP: Promovendo valores para crianças através do movimento corporal", was performed in a public school in a suburb of Ribeirão Preto, the Parque Ribeirão Preto, by two students and a supervisor, a psychologist, all authors of this work. The body and athletics tasks performed aimed to diversify motor stimuli and challenges, require different efforts, create opportunities and occasions to enhance the performance of cooperation. From this intervention it is describe the perception, preparation and orientation of sport experiences, converging to the goal of expanding its resources for interpersonal relationships in an ethical record.
} 
This is a descriptive study that presents situations of significant intervention from the field diaries of scholars responsible for operation over about nine months.

Keywords: Sport. Ethics. Psychology.

\section{INTRODUÇÃO}

\section{De maneira geral, o projeto de extensão universitária ora apresentado se in-} sere no campo do esporte socioeducacional, isto é, vale-se de práticas corporais, notadamente práticas esportivas, oferecidas fora do contexto da educação formal, como meio de intervenção educativa junto a crianças e jovens. A partir de saberes da Psicologia do Esporte e do Exercício, uma de suas principais finalidades é aperfeiçoar a formação dos estudantes de graduação envolvidos, dando-lhes a oportunidade de realizarem intervenções supervisionadas, em que a atenção se detenha em examinar e elaborar condutas educativas dialógicas pautadas pelo registro ético. É o exercício de explicitar e se apropriar deste registro que torna seu valor uma referência consciente para os protagonistas das ações interpessoais, sejam estes os jovens atendidos ou os estudantes envolvidos.

Essas duas referências, dialógica e ética, encontram seus aportes em determinada práxis pedagógica, nos saberes psicológicos e na reflexão filosófica que os subsidiam e orientam. Trata-se, portanto, de informar as competências e determinada prática no campo da Educação Física e Esporte de maneira inovadora, visto que raramente a presença da Filosofia na área vem apresentada como algo próprio à sua prática efetiva. É interessante antecipar que não se trata de substituir a prática corporal pela Filosofia, mas de ter a reflexão filosófica como horizonte de ação para intervir na prática corporal em situação, centrando a conduta nas pessoas envolvidas [5]. Para isso, são propostas modificações em tarefas corporais convencionais que sejam pessoalmente significativas para os envolvidos, isto é, que não sejam automáticas, mas sim mudanças cujo sentido se faça claro para seus protagonistas.

Antes de detalhar os objetivos do projeto, o presente artigo introduz sucintamente a opção conceitual que iluminou a tarefa de orientação pelo registro ético. Dos objetivos segue-se à descrição do método aplicado, bem como ao relato do contexto, das atividades, da dinâmica e do movimento engendrado pela percepção, elaboração e ação dos envolvidos: supervisor, bolsistas e jovens.

\section{$O$ registro ético}

O filósofo francês Paul Ricouer (1913-2005) conceitua a ética sintetizando-a em uma sentença com três partes: "intenção de vida boa, com e para os outros, em instituições justas” [6, p. 162]. A primeira parte alude a uma convenção que distingue ética de moral, cabendo à segunda o caráter de interdição, enquanto a primeira, afirmativa, sinaliza o desejo de felicidade ou, em outras palavras, o desejo de ter a vida realizada. Se a questão ética, portanto, pede como resposta um sentido de vida boa ( $O$ que quero de minha vida? Que sentido dar à minha vida?), a questão moral pede como resposta o que fazer e, notadamente, o que não fazer para viver a vida boa desejada (Como agir? Do que abdicar?). "Com e para os outros", já que nenhum sentido de realização pessoal pode 
verdadeiramente excluir os outros, isto é, ser estritamente individual, solipsista, não podendo se realizar a sós, com seu protagonista isolado. Portanto, não apenas cada um tem necessidade do outro para a vida ética (com o outro), mas isso implica o desejo de que o outro também a viva (para o outro). Ricouer destaca que a última sentença amplia este desejo ético para o outro sem rosto, ou seja, para o outro além da relação direta de amor e de amizade, tendo nas instituições a exigência do sentido de justiça.

No caso aqui apresentado, os esportes, ou mais amplamente, as práticas corporais desenvolvidas, correspondem às instituições justas, na medida em que os critérios esportivos de avaliação dos adversários que disputam se pretendem critérios imparciais de distribuição de méritos nas ações realizadas. Todavia, se o senso de justiça da prática esportiva é naturalizado como sendo equivalente às suas regras, corre-se o risco de assumir o justo como a mera aplicação rígida destas, perdendo-se de vista a situação e a especificidade de seu sentido. $\mathrm{O}$ alcance desta flexibilidade normativa não está em ceder princípios à força das circunstâncias, segundo qualquer forma de oportunismo moral. Ao contrário, seu alcance está na cuidadosa elucidação de como o registro ético pode ser sustentado pela proposição de novas normatividades. Algumas implicações desta questão comparecem no relato de diferentes momentos das intervenções realizadas, onde adaptações do modo de se praticar o esporte foram realizadas a fim de contemplar dialogicamente o senso de justiça no escopo educativo em questão.

\section{Dos Objetivos e da Práxis}

Por meio da oferta de práticas esportivas destinadas a crianças moradoras do entorno do campus da USP de Ribeirão Preto, previa-se a inserção da comunidade USP em atividades educativas extraescolares e voltadas à juventude. Assim, procura-se aproveitar o apelo que as práticas esportivas têm junto aos jovens para potencializar sua dimensão educativa, sem a pretensão de formar atletas, mas de valorizar a ideia de desenvolvimento integral da pessoa em correspondência com os objetivos e ideais da inserção da extensão universitária junto à comunidade externa.

As práticas propostas consistem basicamente em aulas com atividades recreativas relacionadas às práticas esportivas. $\mathrm{O}$ acompanhamento dos bolsistas propõe tarefas similares aos de uma iniciação esportiva, com a diferença de que há uma especial atenção às intervenções dialógicas. Tais intervenções têm o propósito de favorecer o desencadeamento de um processo que conduza atitudes reativas em direção a atitudes responsivas por parte de seus protagonistas. Por atitudes responsivas entende-se a assunção de um posicionamento pessoal perante as situações que se passam, ou seja, um posicionamento em que gradativamente se toma consciência da responsabilidade pessoal pela ação engendrada. As experiências esportivas servem como aqueles disparadores temáticos concretos que visam vincular, por exemplo, a necessidade de diálogo, cooperação, dedicação e esforço junto aos movimentos corporais nas práticas esportivas, com as exigências de enfrentamento do cotidiano vivido e do projeto de vida pensados criticamente em curto, médio e longo prazo. A atenção conversacional a estes elementos vinculadores é que permite a emergência da prática esportiva como mediação coeducativa. Isso porque se trata de experienciar e elucidar atitudes e valores menos ou 
mais adequados para a efetivação da tarefa corporal que se desenvolve. Os objetivos de cada tarefa desenvolvida mantêm o cuidado com relação à dignidade dos participantes, respeitando-se seus modos particulares de vivenciar o desafio de realizá-los. Em outras palavras, visar à tarefa esportiva não constrange o registro ético, mas, ao contrário, a ele se submete. Disso decorrem as modificações nas atividades situando-as como práticas inclusivas. É assim que as situações vividas delineiam um espaço de transição pessoa/ comunidade e comunidade/pessoa [3]. Sob a orientação dos tutores essas situações vividas querem estimular o enriquecimento de recursos interpessoais para o desenvolvimento, por exemplo, de autonomia e condutas dialógicas. A pedagogia da autonomia [4], portanto, circunscreve a práxis educativa que se procura aplicar.

\section{MÉTODO}

Acima foram expostos princípios que orientam a prática interventiva. Todavia, em não se tratando de uma aplicação técnica, cujos efeitos se curvariam à boa execução de certos mecanismos, o método em questão diz respeito a como potencializar o seu acontecimento. Nesse caso, sublinha-se a compreensão de que a aplicação interventiva é indubitavelmente correlata ao modo de presença dos bolsistas, isto é, da atitude adequada dos mesmos, que apenas pode emergir de um posicionamento progressivamente mais consciente e crítico, ou seja, mais ciente de suas iniciativas e perspectivas educativas em situação. Procurou-se potencializar esse movimento formativo dos bolsistas por meio de três procedimentos.

O primeiro foi a leitura regular e a discussão de partes de Pedagogia da Autonomia, de Paulo Freire. Nesta pequena obra, a densa narrativa crítica do autor exemplifica representações de ser professor e ser aluno, representações de ensino e aprendizado, cujos significados implícitos são trazidos à luz. A narrativa sinaliza que é na ordem do relacionamento pedagógico que o sentido educativo toma forma. O leitor parece constantemente convidado a cotar as asserções do autor com as próprias experiências, com as próprias posições de valor, com as próprias atitudes, colocando em questão a si mesmo enquanto sujeito da educação. $\mathrm{O}$ procedimento de leitura e discussão regular desse texto é, portanto, um movimento que problematiza posicionamentos da tarefa educativa estimulando uma abordagem relacional pautada pelo registro ético.

Semanalmente, os bolsistas participavam das reuniões do Grupo de Pesquisa em Fenomenologia, coordenado pelo supervisor. Essas participações visavam familiarizá-los com o questionamento e com as reflexões analíticas pertinentes a esta escola filosófica. Nesses encontros, ocasionalmente também eram apresentados os desenvolvimentos das atividades de extensão realizadas, a fim de que se ampliasse a reflexão coletiva sobre as ações.

Enfim, o terceiro procedimento adotado foi a realização de supervisões clínicas. Estas são assim chamadas não por guardarem qualquer enfoque terapêutico, mas por realizarem um retorno reflexivo sobre os sujeitos da prática, ou seja, ao trazerem os relatos da situação e de suas atuações, os extensionistas são convocados a colocarem em questão suas próprias condutas, seus pressupostos, valores, fins, preconceitos. Este autoquestionamento, desenvolvido pela prática reflexiva da supervisão clínica, evidenciava como a própria percepção do cenário vivido é naturalmente atravessada por esse conjunto de 
aspectos, merecendo ser problematizado $[5,6]$. Conclusivamente, deve-se realçar que esta problematização não equivale a um questionamento infindável ou arbitrário, mas se orienta pelo norte do registro ético acima apresentado.

\section{RESULTADOS}

\section{Do Contexto e das Atividades}

O projeto foi realizado em uma região humilde da cidade de Ribeirão Preto (SP). A intervenção ocorreu nas dependências da Escola Estadual Professora Glete de Alcântra, localizada no distrito oeste do município. Nessa instituição ocorre um projeto intitulado "Extensão Solidária”, em que participam alunos de diversos cursos da USP, que com auxílio do Consulado Britânico e liderados por estudantes de Direito, oferecem atividades estruturadas, como artesanato, reforço escolar, dentre outras, trabalhando conscientização, autoestima, criatividade e cooperação entre os estudantes que voluntariamente se apresentavam no local todos os domingos no período das $14 \mathrm{~h}$ às $17 \mathrm{~h}$. Nesse conjunto, permitiu-se desenvolver o projeto para que, através das práticas esportivas e do movimento corporal como um todo, fosse possível proporcionar o desenvolvimento de habilidades motoras, controle de equilíbrio e concentração, descontração, disciplina e dedicação por parte dos jovens ali dispostos.

Cerca de 25 crianças participaram do projeto, a saber, meninos e meninas na faixa etária de sete a catorze anos. O grupo não era fixo, nem todos participaram durante todo o período de vigência do projeto. Havia a autorização da direção da escola e, como se mencionou, apoio dos alunos à frente do projeto "Extensão Solidária" que, em várias ocasiões, contribuíram com as atividades estimulando as crianças presentes a participarem, emprestando bolas e outros materiais quando necessário. Como o espaço era aberto ao público e sem restrições, crianças de outras escolas da mesma localidade também frequentavam o local e participavam das atividades. Mesmo sendo de escolas diferentes todas as crianças se conheciam e conviviam cotidianamente.

As práticas efetuadas foram, principalmente, as de esportes mais convencionais, como o futebol e o vôlei, porém outras atividades propostas foram aceitas, como o handebol, o slackline e também o frisbee. Os dois últimos esportes, por serem novos e desconhecidos, provocaram grande interesse dos participantes. Também foram realizados diversos jogos e gincanas com brincadeiras populares, como corrida do saco, cabo de guerra, jogos com bambolês e outros.

Todas as práticas foram refeitas em momentos diferentes, de forma intercalada, uma em cada intervenção. $O$ futebol foi a que mais se repetiu, pois se levou em consideração a opinião das crianças, que o solicitavam com mais frequência.

\section{Da Dinâmica}

Logo de início ocorriam brigas, que mostravam a dificuldade de convivência harmônica entre as crianças. Estabelecia-se um ambiente de competição, onde algumas delas 
claramente alimentavam a noção de que seu sucesso deveria significar respectivamente o fracasso dos outros [7]. A primeira atividade realizada foi o slackline, que se assemelha a uma corda bamba a uma altura segura do chão e, já aí, foi possível presenciar esse tipo de situação. Depois da devida apresentação, a montagem do equipamento ocorreu com muita dificuldade, já que algumas crianças interferiam a todo momento, puxavam e balançavam a fita. Quando a atividade teve início, sempre que uma criança percorria o trajeto, outra balançava a fita, provocando a queda do colega, de modo a antecipar sua vez de brincar. Nos jogos de futebol, handebol e mesmo vôlei, a marca do individualismo foi muito presente, havendo indisposição de se trabalhar em equipe, com ausência da cooperação básica a um esporte coletivo. Pela percepção dos bolsistas, as crianças pareciam ter a necessidade de serem superiores aos demais nas tarefas, como se a conquista do respeito dos outros dependesse disso. Essa autoafirmação era um dos principais motivos para a ocorrência de discussões e desistências durante as atividades, bem como, principalmente, do eventual uso de violência física.

A grande maioria dos jovens não conhecia o handebol. Acharam que a bola era de futebol e, logo que tiveram oportunidade, colocaram-na no chão e começaram a chutá-la. Foram exercitados troca de passes, arremessos ao gol, controle da bola e trabalho em equipe e, a princípio, alguns tinham muita dificuldade em cooperar, pois na maioria das vezes queriam a bola somente para si.

Já com o frisbee foram realizados jogos que misturavam regras de futebol americano com o arremesso do disco, mas sem contato físico, onde o objetivo era ultrapassar uma linha limite realizando, para isso, passes para os companheiros e bloqueios para evitar que o disco chegasse ao adversário.

Gincanas com brincadeiras populares, utilizando cordas, bambolês e bexigas, foram muito bem-aceitas. $\mathrm{O}$ incentivo para criarem um grito de guerra estimulou a união interna das duas equipes que haviam sido formadas e favoreceu a cooperação entre eles durante a realização das tarefas, como corrida do saco, cabo de guerra etc. Ao final de cada prova repetiam o grito, tornando-se este um momento de encorajamento mútuo e de valorização da diversão, que favorece a experiência de coesão de grupo.

Na prática do vôlei, foram ensinados fundamentos básicos, como saque, toque, manchete e, ao final, foi realizado um coletivo. A princípio os pontos não eram somados, tanto pela necessidade inicial de praticar o que acabaram de aprender e desenvolver habilidades, quanto pela preocupação em não estimular a competição. Percebe-se que, neste momento do aprendizado, os rudimentos dos gestos esportivos se aperfeiçoam mais pelo trabalho de cooperação entre os participantes do que pela busca de pontuação.

Nem sempre era possível impedi-los de brigarem, embora se interviesse de imediato quando isso ocorria. A cada vez em que acontecia esse tipo de situação, procurava-se adverti-los de uma maneira construtiva, orientá-los para que expressassem seu descontentamento para com o outro de uma maneira diferente, sem violência, através do diálogo, desafiando-os a pensar suas atitudes e principalmente tratando-os com carinho, num contraponto à animosidade da situação.

Os meninos agiam e se consideravam fisicamente mais qualificados que as meninas. Disso decorriam comportamentos que as excluíam das práticas, seja porque elas não tinham chance de participar das jogadas, seja porque quando tentavam, sentiam-se 
agredidas e preferiam não participar. Com o tempo, aceitaram mais facilmente a participação das meninas em suas equipes, distribuindo igualmente as responsabilidades e riscos durante os jogos.

Mais de uma vez ficou clara a rivalidade entre os gêneros. Diferentemente, contudo, no caso do vôlei, eram as meninas que procuravam não cooperar com os meninos durante o jogo. Essa atividade foi muito proveitosa: percebeu-se o quanto as crianças gostaram e evoluíram quanto ao trabalho em equipe, realizando os passes para os colegas sempre que possível, mas também se preocupando a todo momento em marcar pontos, de forma a chegar a um vencedor, muitas vezes inventando e alterando o real placar.

Pode-se perceber que o futebol tem um papel imaginário enquanto principal forma de ascensão social e financeira, sendo muito popular nessa região, onde muitos garotos se empenhavam para que pudessem ter uma chance de jogar profissionalmente e ajudarem suas famílias. Sem desacreditar tais expectativas, os bolsistas procuraram também apresentar novas práticas esportivas, a fim de estimular o aprendizado de novas habilidades corporais e a vivência de outros valores nessas práticas. Houve muita dificuldade na tentativa de inserir as novas modalidades naquele ambiente. O futebol, portanto, era a modalidade em destaque em todos os encontros. Qualquer objeto ali presente era impulsivamente tocado com os pés. Fossem bolas de vôlei, handebol, garrafas, e até mesmo o frisbee, o que mais se percebia era a vontade de jogar com os pés.

Nos dois primeiros meses as supervisões clínicas em psicologia do esporte, nas quais os bolsistas relatavam o desenvolvimento dos encontros, aconteciam uma vez por semana. Posteriormente, elas passaram a acontecer em intervalos de duas a três semanas, já que várias das situações vivenciadas tendiam a se repetir e os bolsistas sentiam-se progressivamente mais seguros para assumirem posicionamentos consequentes com o registro ético e coerentes com a práxis dialógica. O aspecto clínico das supervisões permitiu acompanhar e avaliar o desenvolvimento dos bolsistas para lidar com as situações vividas de modo congruente.

\section{DISCUSSÃO}

O que se conferiu com mais clareza foi o enorme interesse desses jovens pelo futebol, que é para eles uma paixão. Muitos desejam se tornar grandes jogadores. A realização de alongamentos, aquecimentos e todos os outros exercícios que auxiliam na preparação física para um melhor desempenho do jogador (os quais as crianças não gostavam de fazer), acabava servindo de exemplo e mote para o tema da necessidade de empenho e disciplina a fim de se alcançar os próprios objetivos. Como, de modo imediatista e natural, as crianças queriam simplesmente a bola, esse foi um dos tópicos abordados também nas conversas antes da realização da atividade. Pelo fato de o futebol comparecer como tema hegemônico de futuro e paixão, as considerações acerca do desejo e da dedicação necessária para realizar tal desejo correspondiam, sem qualquer uso das expressões ética ou moral, ao grande mote para que os jovens se voltassem a si mesmos e àquilo que se demanda deles para haver alguma realização pessoal.

A cada intervenção houve diferentes opiniões e preferências pelos participantes. $\mathrm{O}$ 
slackline foi considerado a mais inusitada de todas as atividades, despertando diferentes reações, como interesse e curiosidade por parte de algumas crianças, medo e receio por parte de outras. Trata-se de um exercício que exige muita concentração, equilíbrio e, para o iniciante, a contribuição de um colega que sirva de apoio enquanto se atravessa a corda. Percebeu-se que as crianças adoraram a novidade e se divertiram muito. Em contrapartida, depois de certo tempo, uma participante tentou derrubar a outra (e esse tipo de atitude tornou-se frequente) enquanto ambas atravessavam a corda ao mesmo tempo, devido à grande distância de uma extremidade a outra, e então, de certa maneira, disputavam o espaço. Foi essencial intervir salientando, para aqueles que tentavam movimentar a corda para que alguém caísse, que era importante cada um esperar a sua vez, pois não se sentiriam bem caso alguém fizesse isso com eles.

Nessa atenção ao outro a partir de si mesmo, isto é, na transposição de si em direção ao outro, potencializa-se o senso de justiça do registro ético. Na advertência realizada junto às crianças, focou-se menos a proibição, o ato de coibir, do que a consequência ampliada da ação. Sem corresponder a uma abstração moral, a advertência se deu de modo concreto na antecipação do prejuízo que a própria criança sofreria quando fosse a sua vez de se equilibrar, caso alguém tivesse o mesmo comportamento de tentar derrubá-la. Com essa conduta esperava-se haver um compartilhamento do sentido de respeitar a vez do outro e ser paciente, pois todos iriam brincar, possibilitando dividir o mesmo espaço sem atrapalhar o colega.

Assim, de uma situação inicial de frequentes conflitos, com desentendimentos e empurrões, atitudes agressivas, uso de xingamentos aos berros, falta de disposição em cooperar, passou-se a uma situação em que, nas últimas práticas realizadas, constatava-se maior interesse por parte dos alunos, que até se dispunham a ajudar os colegas e a montar o equipamento.

Frequentemente, como nos casos do vôlei e futebol, foi importante realizar modificações nas regras para implementar uma abordagem mais cooperativa à aprendizagem [7]. Assim, por exemplo, não se fazia a contagem dos gols ou pontos e se distribuía os mais jovens em posições em que participariam mais dos jogos. Todavia, tais modificações não aconteciam à revelia das crianças e jovens. As mudanças também não ganhavam a simpatia de parte deles, sobretudo daqueles que, sobressaindo-se em relação aos demais na disputa esportiva, preferiam jogos francos e disputados. A proposição das mudanças sempre era acompanhada de uma consulta aos participantes, o que dava a oportunidade de esclarecer o sentido da prática esportiva. Acostumados à imagem limite do esporte profissional, em que os atletas devem dar tudo de si para vencerem, diferentes sentidos para a prática esportiva só podem ser conquistados de modo persuasivo. É aqui que os efeitos da simples aplicação naturalizada das regras de dada modalidade precisam ser explicitados. Trata-se de constatar que, diante da variação de idades e aprendizado das habilidades dos participantes, tais efeitos correspondem a uma transgressão do espírito esportivo, na medida em que não obedecem ao senso de justiça que aquelas mesmas regras pretendem garantir. Os participantes "não privilegiados", mas que, apesar das diferenças que os inferiorizam na disputa, são colocados em pé de igualdade pelas regras, sentem-se injustiçados. Assim, quando as diferenças físicas e técnicas entre os participantes são flagrantes, o próprio senso de competitividade esportiva é iludido. 
As modificações normativas visam redistribuir as oportunidades e objetivos em acordo com as condições e habilidades dos envolvidos a fim de que, ao contrário do efeito exclusivo do esporte de alto rendimento, haja um efeito participativo no qual o senso de disputa seja recomposto. Essa recomposição se dá por uma espécie de nivelamento entre as partes. Como não se trata de selecionar apenas participantes do mesmo nível, mas de pôr em jogo participantes com diferentes condições e habilidades, as mudanças aconteciam conforme os exemplos descritos. Em poucas palavras, desnaturalizar as regras esportivas por meio de novas normatividades práticas equivale a sustentar a terceira parte da sentença ética de Ricouer, aquela que situa o desejo dos sujeitos em instituições justas. As modificações normativas nessas práticas esportivas, ao invés de significarem apenas um efeito psicológico motivador, ao serem objeto de proposta, consulta e esclarecimento entre os envolvidos, tornam-se ações éticas protagonizadas por sujeitos cientes de seus sentidos e de suas possibilidades [2].

Os resultados deste trabalho permitem identificar que o ambiente estabelecido com a realização das atividades intensificou a troca e o uso do diálogo na relação entre as crianças. A percepção dos bolsistas é de que, no início, predominava a individualidade e rivalidade entre meninos e meninas. Com o tempo passaram a conviver melhor e parecem ter aceitado de forma não superficial, mas significativa, as diferenças que motivavam as modificações normativas e estimulavam a participação integrada. Entende-se que isso se desdobrou a partir da postura e das intervenções dos bolsistas, em que formas alternativas de estabelecer os relacionamentos, sobretudo baseadas na consideração pelo interesse do outro e no diálogo, ocupavam o espaço de ações exaltadas e agressivas. Essa conduta abria novas alternativas para o modo de estarem juntos e se disporem a compartilhar tarefas esportivas cujos sentidos foram "reinventados".

\section{CONCLUSÃO}

Parte significativa das intervenções dos bolsistas dizia respeito a buscar alternativas à agressão para lidar com conflitos e a propor modos de conciliação entre as crianças e jovens. Com efeito, não se tratava de limitar a intervenção a apaziguar ânimos mais exaltados, mas de chamar a atenção para o sentido da disputa esportiva. Conforme este sentido era acompanhado da consciência do "efeito" das normas, a intensificação dos desafios esportivos comparecia de modo menos agressivo.

As situações esportivas são caracteristicamente ocasiões de disputa, em que diferentes partes visam superar-se entre si na busca por um mesmo objetivo. A maneira como essa disputa é experimentada e colocada em prática por seus participantes é determinante para a emergência ou não de conflitos, bem como para o nível de agressividade e eventual violência que os acompanhe. $\mathrm{O}$ esclarecimento do sentido da prática esportiva, na situação em que se dá, favorece que a sua experiência seja acompanhada pela conscientização de seu sentido ético. Irrestrito ao sentido moral, repetidamente atribuído ao esporte, o sentido ético não se quer algum tipo de obediência disciplinada a regras naturalizadas e irrefletidas, mas um permanente desafio à convivialidade justa. No que tange à sua dimensão educativa, um vasto potencial deve ser atribuído às qualidades 
próprias ao esporte. Mas é o caráter inerente de disputa que faz do esporte, enquanto instituição idealmente justa, um laboratório socioeducativo ímpar para a formação genuína de pessoas.

\section{REFERÊNCIAS BIBLIOGRÁFICAS}

[1] ANDERSON, A G.; KNOWLES, Z.; GILBOURNE, D. Reflective practice for sport psychologists: concepts, models, practical implications and thoughts on dissemination. The Sport Psychologist, 18, pp. 188-203, 2004.

[2] BARREIRA, C. R. A. Da história da fenomenologia à ética na psicologia: tributo ao centenário de Filosofia como Ciência Rigorosa (1911) de Edmund Husserl. Memorandum, 20, pp. 135-144, 2011. Disponível em: http://www. fafich.ufmg.br/memorandum/a2o/barreirao1. Acesso em: 24 ago. 2012.

[3] COELHOJÚNIOR, A. G.; MAHFOUD, M. A relação pessoa-comunidade na obra de Edith Stein. Memorandum, 11, pp. 8-27, 2006. Disponível em: http://www.fafich.ufmg.br/ memorandum/a11/coelhomahfoudo1.pdf. Acesso em: 23 ago. 2012.

[4] FREIRE, P. Saberes necessários à prática educativa. São Paulo: Paz e Terra, 1997.

[5] MURATA, K. T.; BARREIRA, C. R. A. Reflexividade em saúde: investigação fenomenológica do processo reflexivo prevalente entre os formandos em Educação Física. Avaliação: Revista da Avaliação da Educação Superior (Campinas), 17 (2), pp. 365-390, 2012. Disponível em: http://www.scielo. br/pdf/aval/v17n2/o5.pdf. Acesso em: 23 ago. 2012.

[6] RICOUER, P.Ética e moral. In: . Leituras 1: Em Torno ao Político. Trad. M. Perine. São Paulo: Loyola, 1995, pp. 161-173.

[7] WEINBERG, R. S. Competição e cooperação. In: WEINBERG, R. S.; GOULD, D. Fundamentos da psicologia do esporte e do exercício. Trad. C. Monteiro. 4. ed. Porto Alegre: Artmed, 2008, pp. 121-141.

CRISTIANO ROQUE ANTUNES BARREIRA professor doutor da Escola de Educação Física e Esporte de Ribeirão Preto da Universidade de São Paulo (EEFERP-USP) - e-mail: crisroba@gmail.com.

RENAN ESTEFANO MOREIRA DOS SANTOS bolsista do Programa Aprender com Cultura e Extensão 2011/2012 e aluno de graduação da Escola de Educação Física e Esporte de Ribeirão Preto da Universidade de São Paulo (EEFRP-USP).

JÔNATAS AUg USTO CURSIOL bolsista do Programa Aprender com Cultura e Extensão 2011/2012 e 2012/2013, e aluno de graduação da Escola de Educação Física e Esporte de Ribeirão Preto da Universidade de São Paulo (EEFRP-USP). 